\title{
La comunidad sefardí de Salónica después de las guerras balcánicas (1912-1913)
}

Matilde MORCILLO

Escuela Universitaria del Profesorado, Albacete, Universidad de Castilla-La Mancha

1. La ocupación griega de Salónica y sus repercusiones sobre la POBLACIÓN JUDÍa

\section{1.a. Salónica antes de las guerras balcánicas}

Después del Tratado de Adrianópolis (14 de septiembre de 1829 ), la liberación de Grecia, bajo yugo otomano desde el siglo $\mathrm{XV}$, era un hecho inevitable que se haría realidad un año más tarde, cuando Francia, Rusia y Gran Bretaña, por el Protocolo de 3 de febrero de 1830, establecieron un estado griego independiente ${ }^{1}$. La superficie de la Grecia surgida de aquel tratado no llegaba a los $50.000 \mathrm{~km}^{2}$.

Una nueva etapa se alcanzó en 1913 al finalizar las guerras balcánicas, en las que griegos, búlgaros y serbios lograron arrebatar a los turcos extensos territorios. Grecia se convirtió en un estado de $116.000 \mathrm{~km}^{2}$, extendiéndose hasta Macedonia,

${ }^{1}$ P. Renouvin, Historia de las relaciones internacionales (Madrid 1982) pág. 88; D. DaKIN, The Greek Struggle for Independence, 1821-1823 (University of California-Press 1973) pág. 107; Archivo Histórico Nacional, Madrid (= AHN), Estado, leg. 5.998: Copia de la Convención de Londres del ministro de Estado al embajador de París, Madrid (21 feb. 1833); M. Morcillo, Las relaciones diplomáticas y comerciales de España con Grecia (1833-1913) (Tesis doctoral, Univ. Castilla-La Mancha, Cuenca 1997). 
El Épiro y Creta. Entre las nuevas adquisiciones figuraba Salónica.

Antes de las guerras balcánicas y bajo el gobierno otomano el colectivo de judíos españoles de Salónica gozaba de un clima de tolerancia. Las barreras entre las comunidades no existían. Cada "nación" ${ }^{2}$ tenía su propia administración interna, sus escuelas, sus clubs, sus propias instituciones de beneficencia, su religión y su lengua; disponían incluso de sus propios barrios. Tal situación de convivencia de grupos étnicos diferentes no era específica de Salónica sino algo habitual en todo el Imperio otomano. En Salónica las zonas de hábitat de cada nación estaban delimitadas de manera bastante estricta.

Por su parte, los judíos que vivían desde antiguo en Grecia también disfrutaban de unos derechos que la Constitución liberal helénica de 1864 -modificada en 1911-, había otorgado a todos los ciudadanos, independientemente de su raza o religión.

Dada la evolución económica de la capital de Macedonia, cuya importancia había llegado a todas las partes del mundo, hasta 1900 la competencia económica entre judíos y no judíos no llegó a perturbar el clima de buen entendimiento que reinaba en Salónica. Pero esta buena compenetración se rompió debido a motivos políticos.

Las autoridades de Salónica no ignoraban que en su mayoría los judíos, temerosos de perder su posición económica, eran hostiles a la agitación revolucionaria que reinaba en Macedonia y sólo deseaban el mantenimiento del statu quo.

Tal actitud disgustaba a los irredentistas del territorio macedónico y su capital. Y aunque parecía poco probable que los israelitas de Salónica pudieran poner obstáculos a los deseos anexionistas de los vecinos de los turcos, sin embargo su comportamiento inspiraba profundas enemistades.

Durante siglos las relaciones entre los judíos y los turcos sólo se habían visto turbadas por pequeños incidentes ${ }^{3}$. Frente a

\footnotetext{
${ }^{2}$ La población de Salónica estaba formada por un conjunto de pueblos: judíos, turcos, griegos, búlgaros, etc., cada uno de los cuales recibía en aquella época el nombre de "nación"; vid. N. COHEN-RAK, "Salonique en 1911 à travers La Solidaridad Ovradera", REJ 148 (1989) págs. 477-485: pág. 477.

${ }^{3}$ J. Nehama, Histoire des Israelites de Salonique, vols. VI y VII (Thessaloniki 1978) pág. 739; P. DuMONT, "La structure sociale de la communauté juive de Salonique à la fin du dix-neuvième siècle», Revue Historique 263 (1980) págs. 351-393: pág. 386.
} 
ello, ya desde cuatro años antes de las guerras balcánicas las relaciones con los griegos habían comenzado a enfriarse. El 15 de septiembre de 1908 el "Fharos tis Thessalonikis" ("Faro de Tesalónica') había publicado un artículo muy virulento en el que invitaba a los griegos a declarar la guerra económica a los comerciantes judíos, no comprando nada en sus tiendas. Esto sólo era el principio. A partir de ese momento los enfrentamientos fueron cada vez mayores, lo que contribuyó a aumentar la tensión en la ciudad.

La entrada de las tropas helenas en Salónica el 8 de noviembre de 1912 fue considerada por la comunidad judía como una catástrofe. La población fue saqueada en su totalidad y su hinterland desmembrado. ¿Cuál fue la actitud del colectivo judío? Desde el 10 de noviembre "L'Indépendant", órgano francófono de dicho colectivo, contrastaba con el entusiasmo de los periódicos griegos e invitaba a los vencedores a moderar su triunfo para no alterar el equilibrio de las comunidades. A pesar de su prudencia y reserva, los judíos mostraban su preferencia por los búlgaros, pensando que en una futura Gran Bulgaria, Salónica conservaría su anterior situación y sería el único gran puerto del Oriente mediterráneo. Es más, los búlgaros no adoptarían posturas antisemitas, mientras que bajo los griegos se temía lo peor.

Por otro lado, la agencia telegráfica sólo funcionaba de vez en cuando. Los comunicados otomanos publicados en "L'Indépendant" o en el periódico turco "Yeni Asir» únicamente podían convencer a los ingenuos. En este ambiente de confusión los judíos estaban desorientados y la alarma cundió rápidamente en la comunidad.

Con gran urgencia los sefardíes de Salónica recurrieron a destacadas personalidades y organizaciones judías de Europa para que emplearan su influencia con las grandes potencias y evitaran que la ciudad fuera anexionada por los griegos y mantener así el dominio turco. En caso de que esto no fuera posible, aspiraban a internacionalizar la ciudad, convirtiéndola en un puerto libre de modo que no pudiera caer bajo control griego. Los judíos europeos intervinieron aunque sin éxito ${ }^{4}$.

${ }^{4}$ Archivo del Ministerio de Asuntos Exteriores, Francia (= AMAEF), Nueva Serie, Turquía, vol. 138: Carta del Comité Central de la Alliance Israélite Universelle (30 dic. 1912). 
La comunidad judía se sentía desamparada, abatida por el cataclismo que se avecinaba sobre Macedonia y temerosa de perder su posición económica; a fin de cuentas los judíos, como sus correligionarios de Hamburgo, eran uno de los escasos grupos leales al Imperio otomano, en una época en que los nacionalismos separatistas habían penetrado profundamente en las poblaciones musulmanas y en que los propios turcos gobernantes habían comenzado a abandonar el otomanismo por un nacionalismo turco más exclusivo.

Si bien durante los años 1908-1909, los judíos habían prestado un considerable apoyo al movimiento antiotomano de los Jóvenes Turcos, ello no impedía que todos los sectores de la población israelita sintieran una auténtica lealtad hacia la patria otomana y siempre que habían tenido la oportunidad los judíos habían contribuido en la medida de lo posible a evitar el colapso del gobierno otomano en las regiones del conflicto ${ }^{5}$.

A medida que se aproximaba el desenlace de la sangrienta tragedia balcánica, todas las nacionalidades dispares que se codeaban en Macedonia se preguntaban con ansiedad lo que el futuro les iba a reservar bajo el punto de vista político y económico ${ }^{6}$. Entre tanto, los judíos súbditos griegos y de potencias extranjeras intentaban defender sus casas y tiendas contra un eventual pillaje. La población israelita daba muestras de una gran reserva a la espera de ver qué actitud iban a adoptar sus nuevos dueños. Un testigo, Yosef Néhama, decía (1912):

¿Cuál será nuestra suerte en las nuevas circunstancias en que nos hallamos? Se teme lo peor. Muchos hablan de una ruina total y de un éxodo masivo de Salónica como consecuencia del antisemitismo y de las nuevas condiciones económicas engendradas por la guerra.

Bakalum [veamos], como dirían nuestros viejos dirigentes, y añadamos, al igual que ellos, siempre juiciosos y seguros de sí mismos, Allah kerim [Dios es bueno]?

${ }^{5}$ A. Rodrigue, "Los sefardíes en el imperio otomano", en Los judios de España, ed. E. Kedourie (Barcelona 1992) págs. 173-194: pág. 192; véase E. Benbassa, Un grand rabbin sépharade en politique 1892-1923 (París 1990).

${ }^{6}$ Archivo del Ministerio de Asuntos Exteriores, Madrid (= AMAE), Corresp. (Salónica), leg. 2.042: De un Despacho del cónsul de España en Salónica, Antonio Luqué, al ministro de Estado (Salónica 1913).

${ }^{7}$ Archivos de la Alliance Israélite Universelle (= AAIU), Grecia, I.C., 51: Carta de Josef Néhama (12 nov. 1912), citada por Rodrigue "Sefardíes" pág. 194. 
Cuando la contienda todavía no había terminado, la administración griega se puso en funcionamiento: el príncipe Nicolás fue nombrado gobernador militar y comenzó la helenización de la ciudad, frenada en parte por la presencia de los soldados búlgaros, que ejercían una especie de condominio y protegían al periódico "Bâlgarin", que no cesaba de criticar la actitud griega. El 14 de diciembre un incidente enfrentaba a los soldados búlgaros y griegos; la violencia termina y el periódico desaparece.

Finalmente, el Tratado de Bucarest de 1913 ponía fin a las guerras balcánicas y a partir de ese momento Salónica pasaba a poder de Grecia ${ }^{8}$.

\section{1b. Salónica después de las guerras balcánicas}

Los problemas para los judíos comenzaron tras la ratificación del Tratado greco-turco de noviembre de 1913 por el que se abolía en la nueva provincia helena el régimen de las Capitulaciones así como todos los privilegios derivados del mismo , constituyendo el elemento judío un cuerpo extraño en medio de la homogénea organización nacional de Grecia. Ello podía provocar una cierta tensión en el seno del gobierno heleno, máxime cuando Salónica era el punto más sensible del país y la segunda ciudad más importante del reino.

Por su parte, los soldados griegos, exaltados todavía por los triunfos que acababan de obtener, desconfiaban de una población que ignoraba su lengua y sus tradiciones, dando crédito a toda suerte de calumnias contra los judíos y dejando que se cometieran contra ellos actos de violencia. Si esto sucedía entre la tropa griega, la animadversión hacia los hebreos aún era mayor entre los oficiales y jefes, a quienes, acostumbrados a ser recibidos por la muchedumbre como libertadores, irritaba la frialdad con que habían sido acogidos en Salónica y ello a pesar de que el gobierno había prometido dar todo tipo de facilidades a la población judía para su integración.

Las nuevas autoridades civiles castigaron con severidad a los responsables de los complots antisemitas y Venizelos envió a

${ }^{8}$ B. LoRY, "1912, les Hellènes entrent dans la ville», en Salonique, 1850-1918: La "ville des Juifs « et le réveil des Balkans, ed. G. Veinstein (París 1992): págs. 247-254.

${ }^{9}$ AMAE, Polít. (Grecia), leg. 2.516: Despacho del cónsul de España en Salónica, Antonio Luqué, al ministro de Estado (Salónica 31 dic. 1913). 
Salónica a importantes personalidades israelitas de Grecia con la misión de convencer a sus correligionarios de los beneficios de la dominación helénica.

Asimismo Venizelos adoptó las siguientes medidas tendentes a favorecer a los judíos: 1) exención del servicio militar sin perder el derecho al voto a cambio de pagar una cierta cantidad de dinero durante un período de tres años; 2) permiso para respetar el šabat en Salónica; 3) derecho a participar en la administración pública; 4) derecho a continuar llevando las cuentas en su propia lengua (judeoespañol); 5) libertad de prensa judía; 6) colaboración entre veterinarios civiles y oficiales para asegurar la observancia de las leyes dietéticas judías; 7) ayuda del gobierno de 1.200 dracmas a las comunidades judías de más de cincuenta familias y subsidios a diversas asociaciones judías y al club atlético sionista Makabí; y 8) exención de todas las tasas para la importación del pan ázimo, de uso preceptivo durante la Pascua judía ${ }^{10}$.

La familia real compartía estas medidas y apoyaba a los judíos. Prueba de ello fueron las continuas visitas de los reyes a los sefardíes de Salónica; la reina Olga iba frecuentemente acompañada de damas judías de la aristocracia, al tiempo que se dedicaba a actividades benéficas, lo que aumentaba su popularidad entre la población israelita. Incluso el rey Jorge, cuando recibió a siete miembros de la delegación de la comunidad sefardí de Salónica, les manifestó:

Soy un gran amigo de vuestra nación, porque tengo muchos amigos entre vuestros correligionarios, en Grecia y en Copenhague. Cuando visité Larisa estuve en casa de un judío, mi amigo Haimatchi Cohen. Yo quisiera decirles de nuevo, que los judíos tienen en mí a un gran amigo ${ }^{11}$.

A pesar de tales gestos de benevolencia hacia los hebreos, ¿podían éstos tratar como hermanos consanguíneos a los soldados griegos después de todos los desmanes cometidos entre la población? Evidentemente no. En noviembre de 1912, Yosef

\footnotetext{
${ }^{10}$ Véanse los artículos de R. Molno, "Venizelos and the Jewish community of Salonika (1912-1919)", Journal of the Hellenic Diaspora 13 (1986) págs. 115-116: pág. 113; $y$ "The Jewish community of Salonika and its incorporation into the Greek state 1912-1919", Middle Eastern Studies 24 (1988) págs. 391-403.

$"$ AAIU, Grecia, I.C., 49: Carta de M. Cohen al presidente de la Alliance Israélite Universelle (4 dic. 1912), citada por MolHo "Venizelos" pág. 114.
} 
Cohen, profesor de la escuela de la Alliance Israélite Universelle en Salónica, decía en una carta a su superior en París:

Está hecho ... y tan pronto como los turcos han abandonado la ciudad el antisemitismo ha alzado su fea cabeza con la entrada de los primeros soldados griegos en la población.

Hay que decir que el judío, sumido en una gran tristeza, no tiene tiempo para las celebraciones que tienen lugar en la ciudad. Ha adoptado la actitud correcta y digna que corresponde a los vencidos. No puede acoger con entusiasmo al vencedor que pisotea sus más preciados sentimientos. Es cuando uno pierde lo que tiene cuando aprecia su verdadero valor, y los judíos, que siempre han reconocido las raras cualidades de tolerancia y buena voluntad del pueblo turco, sienten hoy que han perdido en este terrible cataclismo a sus más fuertes y seguros protectores. Los más sencillos del pueblo han venido a mí con lágrimas en los ojos diciendo que no pueden resignarse a la ruina de la patria otomana. E incluso yo, que me he quejado a menudo de los insignificantes problemas burocráticos creados a las escuelas por la vieja administración, incluso yo me siento anonadado cuando veo a nuestros pobres soldados deambular a la aventura por las calles sin armas, en busca de refugio y de un pedazo de pan. Los griegos han invadido los cuarteles y nuestros soldados están en la calle ... Hoy, terribles rumores circulan por las calles. Ha habido acusaciones contra los comerciantes judíos de que han estado vendiendo bebida envenenada a los soldados griegos ... Una larga y dolorosa experiencia nos ha enseñado que el antisemitismo siempre ha sido así, que siempre adopta esta forma que acaba dando lugar a masacres ${ }^{12}$.

No podía ser de otra manera; para Grecia, Salónica estaba ocupada por un elemento extranjero desde el siglo $\mathrm{XV}$, aunque la presencia de los judíos en Salónica se remonta a la antigüedad como lo atestiguan las epístolas de San Pablo en el siglo I dirigidas a la Iglesia de Tesalónica, formada en el seno de la antigua comunidad judía de la ciudad. En 1170 el viajero Benjamín de Tudela dice que la comunidad judía contaba por entonces con 500 miembros.

La población judía de la ciudad se vio considerablemente aumentada desde finales del siglo $\mathrm{XV}$, a raíz de la expulsión de los judíos decretada en España en 1492, con la que se inicia la

${ }^{12}$ Citado por Rodrigue «Sefardíes" págs. 193-194. 
gran dispersión sefardí por Europa y muy especialmente por el Imperio otomano ${ }^{13}$. Los expulsados de España fueron muy bien recibidos por la Sublime Puerta y, como es sabido, el Imperio otomano fue siempre un refugio seguro para los hebreos, ya que la política otomana siguió con ellos el sistema islámico de la dhimma ${ }^{14}$.

Por el contrario, los judíos no debían nada a Grecia ni habían tenido ninguna relación ni lazo político con ella. ¿Acaso podía el gobierno heleno, por el hecho de ser israelitas, someterlos a unas leyes diferentes de las del resto de la población?

Según el primer recuento efectuado por la administración griega en 1913, los judíos de Salónica representaban al menos el $50 \%$ de la población, siendo además el colectivo más numeroso, ya que, según Rena Molho, los 157.889 habitantes de Salónica se repartían así: 61.439 judíos, 45.889 turcos, 39.956 griegos y una porción mucho menos importante de búlgaros, occidentales $\mathrm{y}$ armenios ${ }^{15}$.

Había que favorecer la convivencia de todos. Las autoridades helenas se empeñaban en decir a los hebreos que no debían temer nada de ellas: todo seguiría igual que bajo el poderío otomano. De hecho, todavía no se había alterado en nada el recién abolido régimen de las Capitulaciones.

Sin embargo, los judíos, recelosos, pensaban pedir a Europa la autonomía política de Salónica, para que fuese declarada ciudad libre. El cónsul español en dicha ciudad, Antonio Luqué, en su correspondencia con España comunicaba que un grupo de israelitas de Salónica estaba tratando de hacer llegar clandestinamente a poder de los gobiernos de las grandes potencias un proyecto, elaborado por el barón Joseph Schwegel, relativo al porvenir político y económico de Salónica. En él se proponía que la ciudad fuese proclamada libre y neutral, situada bajo las garantías internacionales y dejando una zona franca para Austria.

Se sabía que el proyecto lo tenía ya en sus manos el cónsul de Austria y que pronto lo iba a recibir el de Inglaterra; también se rumoreaba que iba a pedirse la adhesión de las principales

${ }^{13}$ G. Veinstein, «Un paradoxe séculaire», en Salonique págs. 42-63: págs. 42-44.

${ }^{14}$ Rodrigue "Sefardíes" pág. 174.

${ }^{15}$ R. Molho, "Le renouveau...», en Salonique págs. 64-78: pág. 65. 
cámaras de comercio de Salónica. Resultaba imposible saber el número de israelitas que apoyaba dicho proyecto, dado el sigilo con el que se llevaba el asunto. Los conjurados trabajaban aisladamente e incluso algunas destacadas personalidades lo desconocían.

El diplomático español había tenido noticia de todo ello porque uno de los más importantes súbditos judíos de Salónica le había hecho llegar el texto. En caso de éxito, le había comentado el mismo sujeto, la comunidad judía, que al menos por su influencia iba a ser la predominante en la nueva entidad internacional, vería con satisfacción el nombramiento de un gobernador español. Esta designación, pensaba el cónsul, no podía ser considerada con desagrado por las potencias, ya que España no les inspiraba ningún recelo, habida cuenta de su talante neutral, y en cambio sí tenía intereses morales que invocar ${ }^{16}$.

En opinión del cónsul español Antonio Luqué lo primero que había que hacer era que la voz israelita se oyera en el Congreso internacional que en esos momentos se celebraba, sin detenerse a averiguar las dificultades que conllevaba aquella aspiración españolista ni sus ventajas y desventajas, porque eso correspondía a España. Parecía posible que muchos israelitas súbditos de otras potencias no fuesen partidarios de un gobernador español; pero si las simpatías por España entre los judíos salonicenses no eran unánimes, al menos eran bastante generales ${ }^{17}$. El proyecto, sin embargo, no prosperó.

Algunos judíos habían pensado incluso emigrar a Tierra Santa, pero la incuria del país hacía imposible absorber una inmigración más o menos masiva, aparte de que muchos hebreos tampoco estaban dispuestos a abandonar los hogares que habitaban desde hacía más de cuatro siglos para comenzar de nuevo una vida errante, arruinando su floreciente situación financiera.

Se sabe que a principios del siglo xx los judíos de Salónica jugaban un papel determinante en la vida de la ciudad. Partici-

\footnotetext{
${ }^{16}$ M. MORCILlo, "Aproximación al pensamiento del sefardita de Salónica Alberto Asseo (1912)", Revista de la Facultad de Humanidades de Jaén 2 (1992) págs. 81-90: pág. 86 .

${ }^{17}$ AMAE, Corresp. (Salónica), leg. 2.042: Despacho del cónsul de España en Salónica, Antonio Luqué, al ministro de Estado (Salónica 26 mayo 1913).
} 
paban en la mayor parte de las actividades económicas y estaban representados en todas las clases sociales. Marcaban con su presencia la fisonomía de Salónica, hasta el punto de que las tiendas cerraban los sábados, pues la mayor parte de los cafés, restaurantes, talleres, almacenes, etc., vivían de la clientela israelita ${ }^{18}$.

Todo ello debió influir en el gobierno ateniense cuando trató de atraerse al elemento judío y de hacerles ver que debían permanecer tranquilos y continuar su vida habitual, confiando en la justicia y en los sentimientos de Grecia ${ }^{19}$. Así lo comunicaba el nuevo cónsul español Manuel de la Escosura a su gobierno de Madrid:

Las instituciones de estudios griegos se multiplicarán y abrirán sus puertas a la población israelita. En poco tiempo, todos los judíos pasarán por estas escuelas y hablarán la lengua griega tan bien como sus correligionarios de Atenas. No tardará en llegar el día en que los judíos de Salónica se consideren como ciudadanos de pleno derecho ${ }^{20}$.

No opinaban lo mismo los israelitas de Salónica, quienes creían que la helenización de la ciudad suponía no sólo su declive económico, sino también el político, y que se verían forzados a emigrar masivamente al enfrentarse a sus nuevos amos. Pero, dado que en un primer momento el gobierno griego concedió numerosas ventajas para integrarlos y gracias al tacto que habían mostrado las autoridades helenas, los judíos se fueron adaptando a la nueva situación mejor de lo que se esperaba.

Sin embargo, el período de posguerra trajo consigo un empeoramiento del estatuto jurídico de los israelitas salonicenses, que se vieron amenazados hasta en su propia existencia física. Una gran parte de la población se había marchado ya a raíz del gran incendio de 1917, que había devastado la ciudad. Luego el régimen griego instauró una política de impuesto directo que obligó a exiliarse a los judíos más ricos. Por último, la llegada

18 Dumont "Structure" pág. 353.

19 AMAE, Corresp. (Grecia), leg. 1.604: Despacho del cónsul de España en Salónica, Manuel de la Escosura, al ministro residente de España en Grecia (Salónica 2 en. 1915), citado por M. NordaU, "Grecia y los israelitas de Salónica", $L$ 'Indépendant (Salónica 28-29 en. 1914) págs. 5-6.

${ }^{20}$ AMAE, Corresp. (Salónica), leg. 2.042: Despacho del cónsul de España en Salónica, Manuel de la Escosura, al ministro de Estado (Salónica 30 en. 1914). 
masiva de refugiados griegos en 1922 como consecuencia de los intercambios de población entre Grecia y Turquía obligó a numerosos judíos a abandonar la ciudad. Por esa misma época, las autoridades griegas promulgaron varios decretos antisemitas que en algunos casos dieron lugar a pogromos ${ }^{21}$.

En 1923, por orden del general Pangalos, gobernador de Salónica, se publicó en los periódicos de la ciudad una serie de disposiciones. Según éstas, todos los habitantes de Salónica -ningún extranjero estaba exento-, debían estar provistos de un documento especial de identidad expedido por el alcalde y visado por la policía, que debían presentar cuantas veces lo requirieran las autoridades. El que contraviniere la orden se vería sometido a un consejo de guerra.

La reacción del colectivo sefardí no se hizo esperar. Lleno de pánico, acudió al cónsul español en Salónica, Teodoro Varela y Gil -en menos de diez años se había cambiado tres veces de cónsul-, para que velase por sus intereses. Desde allí se les aconsejó que presentasen ante las autoridades de Salónica el certificado de identidad completo, con fotografía, escrito en griego y visado por la Prefectura, además del certificado de nacionalidad consular, que también estaba redactado en griego ${ }^{22}$.

Los días de la Monarquía en Grecia estaban contados, pero no por ello iba a mejorar la situación de los sefardíes. A finales de 1923 se celebraron elecciones generales en el país, dando el triunfo a los venizelistas. Lo más destacado en las mismas, según palabras del cónsul español ${ }^{23}$, fue

la abstención de los judíos, que de los 80.000 que más o menos residían en Salónica, unos 15.000 debían haber votado. Es evidente que no se abstuvieron ni por motivos políticos ni por estar en contra de uno u otro partido, sino únicamente por haberles obligado a votar separadamente en un sector único y exclusivo para diputados israelitas, medida que aquéllos consideraron vejatoria y depresiva. Los cuatro diputados hebreos

${ }^{21}$ J. Barnar, "La comunidad judía de Salónica (1430-1943)", en Los judios de España: Historia de una diáspora, 1492-1992, ed. H. MÉCHoulan (Madrid 1993) págs. 382-393: pág. 391.

${ }^{22}$ AMAE, Polít. (Grecia), leg. 1.605: Despacho del cónsul de España en Salónica, Teodoro Varela y Gil, al ministro de Estado (Salónica 30 abril 1923).

${ }^{23}$ AMAE, Corresp. (Grecia), leg. 1.605: Despacho del cónsul de España en Salónica, Teodoro Varela y Gil, al ministro de Estado (Salónica 20 dic. 1923). 
que eran elegidos por Salónica salieron triunfantes solamente por 25 votos.

La votación fue un triunfo para los venizelistas que obtuvieron 200 escaños, frente a los 120 de los republicanos, pero éstos fueron tan firmemente apoyados por los oficiales del ejército y de la marina, que el rey Jorge II abandonó Grecia sin abdicar, hasta que el plebiscito de abril de 1924 proclamaba oficialmente la República.

Si bajo la Monarquía los judíos estuvieron vigilados, su temor no disminuyó con la República; ésta incluso llegó más lejos al dañar sus intereses económicos. En 1927 se constituyó un grupúsculo antisemita que desencadenó el boicot de los negocios judíos y se fundó el periódico antisemita "Makedonia" ${ }^{24}$.

En 1928 el gobierno griego creó únicamente para Salónica un nuevo impuesto sobre los derechos de aduana, destinado a la construcción de carreteras, que variaba entre el 2 y el $7 \%$. Solamente al puerto se le aplicó el $5 \%$. Si a esto añadimos otro impuesto del $3 \%$ para el sostenimiento de la Universidad y el $1 \%$ para obras benéficas, se podrá comprobar fácilmente cómo se lastimaban los intereses de los judíos, dado que en su mayoría eran comerciantes.

Así lo hacía saber el cónsul español Teodoro Varela y Gil ${ }^{25}$ en correspondencia con el gobierno de Madrid:

Más grave, si cabe, fue la posición de los israelitas con la llegada de un enorme contingente de refugiados helenos, ocasionando la quiebra de varias casas de comercio de sefardíes, súbditos españoles, originando la emigración de las familias más pudientes, en número de 120 , temiendo que continuase el éxodo de persistir aquellas medidas. Algunos gobiernos, sin embargo, perjudicaron aún más a los judíos implantando la denominada "Institución de Reposo o Descanso Obligatorio del Domingo». Con la nueva medida se ven obligados a descansar dos días seguidos.

En 1931 un pogromo organizado contra los habitantes judíos de uno de los suburbios de Salónica originó una gran emigración a Palestina y a otros países. En este contexto, en definitiva, debe

\footnotetext{
24 BARnal "Salónica» pág. 391.

25 AMAE, Polít. (Grecia), leg. 2.518: Despacho del cónsul de España en Salónica, Teodoro Varela y Gil, al ministro de Estado (Salónica 17 ag. 1929).
} 
entenderse la situación de los hebreos con la República hasta la ocupación nazi de la ciudad en 1940.

2. GEstión de Los diplomáticos españoles en favor de los SEFARDíES DURANTE LA PRIMERA GUERRA MUNDIAL

El estallido de la guerra europea de 1914 significó para los griegos, lo mismo que para sus vecinos de los Balcanes, la intensificación de una crisis iniciada dos años antes. Pronto surgirían las primeras escisiones y el enfrentamiento en relación con la contienda entre el rey griego Constantino y su primer ministro Venizelos, quien en 1917 pactó en secreto con las potencias de la Entente la formación de un gobierno provisional en Salónica ${ }^{26}$.

Desde los primeros días de la conflagración, el temor de que el país se viera implicado en la guerra era palpable entre la población, principalmente israelita, y sobre todo entre los judíos que recientemente habían adquirido la nacionalidad griega tras la incorporación de Salónica a Grecia en 1913. Por ello, como ya he dicho en otro trabajo ${ }^{27}$, muchos judíos de origen español optaron por solicitar al gobierno de España que se les reconociera como súbditos españoles para no tener que cumplir el servicio militar. El proceso de decadencia de la comunidad de Salónica era ya un hecho: muchos judíos emigran a Europa y a América, amén de los más de 10.000 que se habían trasladado a Turquía al año siguiente de la conquista helena ${ }^{28}$.

Lo que realmente querían todos los que habían decidido acudir al consulado español era que se les concediese la ciudadanía española, evitando así el ser tratados como enemigos por Francia y Gran Bretaña, habida cuenta la neutralidad de España en la contienda, las tendencias proalemanas del soberano heleno y la posterior entrada de Grecia en la guerra por Venizelos en 1917.

${ }^{26}$ R. MOLho, "Thessalonique après 1912: Propagandes étrangères et communauté juive", en La France et la Grèce dans la Grand Guerre (Thessalonique 1992) págs. 47-60: pág. 48.

${ }^{27}$ M. Morcillo, "Essai sur la communaute séfardie de Salonique pendant le premier tiers du XXe. siècle», Lo Nishkach 8 (1993) págs. 42-47: pág. 42.

${ }^{28}$ Rodrigue "Sefardíes" pág. 193. 
No obstante, la realidad era muy distinta, pues primero el gobierno español tenía que reconocer a aquella comunidad de hebreos como súbditos suyos, asunto que estuvo acompañado de numerosos obstáculos y que se resolvió lentamente.

El primer incidente surgió en Salónica al finalizar las guerras balcánicas, en el momento del traspaso de poderes del gobierno turco al griego en 1913. Según decía el cónsul español, Manuel de la Escosura, tal cuestión no se hubiese planteado si España hubiera deseado tener bajo su protección a los sefardíes salonicenses en otro tiempo, cuando todavía estaba en vigor el conocido régimen de las Capitulaciones en el Imperio otomano. Cuando el gobierno español se dio cuenta del peligro que podía correr la comunidad israelita, Grecia se le había adelantado, conocedora de lo beneficioso que podía resultarle conservar la población judía, dada su actividad comercial y financiera ${ }^{29}$.

El enfrentamiento entre el ejecutivo ateniense, tras negarse al reconocimiento de los sefardíes como súbditos españoles, y el gobierno de Madrid era imparable. Había que buscar un argumento justificativo para presionar a Grecia.

En principio sirvió de ejemplo el hecho de que varios israelitas salonicenses emigrados a Serbia, después de los primeros obstáculos para ser reconocidos como súbditos españoles por el gobierno serbio y al agravarse la situación nada más comenzar la guerra, puesto que podían ser llamados al servicio militar en Serbia, volvieron a Grecia para solicitar dicho reconocimiento. Recordemos que Austria declaraba la guerra a Serbia en julio de 1914.

Dichos sefardíes regresaron a Salónica provistos de una carta de recomendación del cónsul de España en Serbia, para que el canciller español del consulado salonicense solucionase el conflicto. Finalmente, las buenas gestiones del ministro residente español en Atenas, conde de Velle, dieron sus primeros frutos en Uskub, capital de la Serbia de entonces, donde obtuvieron el reconocimiento como españoles todos los judíos que presentaron el certificado de inscripción del consulado de España en Salónica.

${ }^{29}$ AMAE, Corresp. (Grecia), leg. 1.604: Despacho del cónsul de España en Salónica, Manuel de la Escosura, al ministro residente de España en Grecia, conde de Velle (Salónica 2 en. 1915). 
El propio conde de Velle no podía ocultar su entusiamo y lo comunicaba al gobierno de Madrid con estas palabras:

Era todo un éxito que había que celebrar y motivo más que suficiente para que Grecia no se resistiera a reconocerlos, dado el escaso número de sefardíes que el gobierno español, mostrándose en extremo prudente, había sólo admitido como súbditos suyos en 1914. Unas 190 familias, que sumaban sobre 900 individuos, de los cuales 230 eran mujeres, y que el total había ya disminuído, puesto que algunas familias habían emigrado a Serbia ${ }^{30}$.

El ejecutivo de Madrid no quería con aquella medida sentar ningún precedente en lo sucesivo. Es más, ignoraba los resultados que había obtenido Austria en la cuestión de los súbditos austríacos, planteada en términos muy diferentes a los de España, que no tenía intereses políticos ni económicos en el área mediterránea-oriental y sólo quería evitar, desde su posición como potencia neutral en la contienda, que los sefardíes súbditos españoles tuviesen que ir al frente. Austria, en cambio, estaba interesada en conservar a sus súbditos judíos en Grecia, habida cuenta de sus aspiraciones en la zona.

Esto explica que, después de 1912, Austria, junto con otras potencias, comenzase a hacer propaganda entre los judíos sobre las consecuencias que les podían acarrear sus nuevos amos griegos. Vistas así las cosas, España se hallaba en condiciones más favorables que Austria para obtener el reconocimiento de sus súbditos.

No debió pensar lo mismo Venizelos, quien a pesar de sus primeros recelos de que los judíos pudieran hacer la competencia a los griegos, trataba luego, ante las insistencias del gobierno español, de atraerse las simpatías del elemento israelita. Paralelamente y según refiere el conde de Velle, el cónsul de España en Salónica, Manuel de la Escosura, intentaba obtener buenos informes para las autoridades locales sobre los judíos españoles. Sin embargo, a pesar de aquellas diligencias para presionar al jefe de gobierno griego, la cuestión sobre los judíos seguía sin resolverse, paralizada al parecer y según palabras del representante español "por sospechar las autoridades griegas de la ilegalidad de aquellos certificados de inscripción", sospechas

30) AMAE, Corresp. (Grecia), leg. 1.604: Despacho del ministro residente de España en Grecia, conde de Velle, al ministro de Estado (Atenas 19 en. 1915). 
que trataba de disipar el cónsul afirmando repetidas veces que se hicieron bajo la atenta mirada de la policía helena ${ }^{31}$.

Lo único positivo era el reconocimiento de los judíos españoles como tal por el gobierno de Uskub, gestión realizada por el diplomático español conde de Velle, lo que contrasta con la negligencia del diplomático español Sr. Ory, quien como decía el ministro de Estado en correspondencia al propio conde de Velle

dejó escapar la oportunidad favorable para tener el consentimiento de la Sublime Puerta a la pseudo-naturalización de los judíos de Salónica. El cumplimiento del requisito de las inscripciones, nadie con más motivo que el gobierno turco podía haberlo exigido cuando los israelitas solicitaron ser reconocidos súbditos griegos, y si las autoridades otomanas han prescindido de él, las griegas serían más "papistas que el Papa" si se negaran a pasarlo por alto, tanto más cuanto no era aventurado afirmar que más de una vez el gobierno griego había concedido a súbditos turcos la nacionalidad helena «sin pararse en barras" 32 .

Planteada la cuestión en estos términos, si Grecia no accedía a reconocerlos era porque detrás de todo ello existía un problema de fondo más importante que el puro trámite diplomático, dado que sus intereses económicos y comerciales estaban en juego tras el descrédito del comercio griego y la industria española durante la guerra ${ }^{33}$, aún cuando con ello pudiera provocar una tirantez en sus relaciones diplomáticas con España, que por cierto en aquel momento eran cordiales.

Grecia y España, conocedoras del impacto que había causado tal desprestigio entre la población, comprendieron el papel importantísimo que podían desempeñar no sólo Salónica, cuyo puerto era el de mayor concentración comercial de Grecia, sino también sus comerciantes.

\footnotetext{
${ }^{31}$ AMAE, Corresp. (Grecia), leg. 1.604: Despacho del ministro residente de España en Grecia, conde de Velle, al ministro de Estado (Atenas 19 en. 1915).

${ }^{32}$ AMAE, Corresp. (Grecia), leg. 1.604: Minuta del ministro de Estado al ministro residente de España en Grecia, conde de Velle (Madrid 6 feb. 1915).

${ }^{33}$ M. Morcillo, "Hispania, primera revista española en Oriente», Ensayos 5 (1991) págs. 71-77: pág. 74; y A. PAx, «La industria española en Oriente y los especuladores griegos en Barcelona", Hispania 1 (1919) págs. 18-19.
} 
Así lo exponía el encargado de negocios español Pedro de Prat ${ }^{34}$ a su gobierno en Madrid:

la casi totalidad de ellos son judíos de origen español, que continuaban hablando el judeo-español. Ellos y no otros eran los verdaderos comerciantes experimentados de aquellos riquísimos mercados, con unas técnicas adaptadas a las necesidades y costumbres de esos países.

A tal florecimiento económico había contribuido el proceso de occidentalización que se produce a finales del siglo XIX, logrando los judíos el control de la vida económica de la próspera ciudad. Empresas tan conocidas como las de Gattegno y Burla y otras menos famosas como Botón desempeñaron un papel importantísimo en el comercio con Europa. La exportación de grano, la producción de vino y cerveza y las industrias textil y tabacalera atrajeron el capital y la pericia judía ${ }^{35}$. Los sefardíes eran, en definitiva, los únicos que podrían salvar la comercialización en Grecia de los productos manufacturados en España.

Tanto el gobierno griego como el español tenían la mirada puesta en el colectivo judío de Salónica, debido al interés comercial y económico que dicha comunidad representaba para el comercio heleno, no menos que para el español -aunque tardara bastante tiempo en admitirlo-, motivo suficiente para que Grecia obstaculizase la cuestión del reconocimiento de los judíos, si bien Serbia los había reconocido como súbditos españoles, con lo que se había evitado el perjuicio que les hubiera ocasionado la guerra, dada la implicación de esta potencia en el conflicto.

Por último, gracias a las diligencias del conde de Velle y del encargado de negocios Pedro de Prat, en 1914 el gobierno de Atenas accedió a reconocer a aquella comunidad de 900 individuos como súbditos españoles, además de conceder un plazo para que los que tuviesen la documentación en regla y no la hubiesen presentado a tiempo lo hicieran en aquel momento. A

${ }^{34}$ AMAE, Polít. (Grecia), leg. 2.517: Despacho del encargado de negocios de España en Grecia, Pedro de Prat, al ministro de Estado (Atenas 24 nov. 1919).

${ }^{35}$ I. Emmanuel, "Los Jidios de Salonique", en Zikhron Saloniki, ed. D. A. ReCANATı (Tel-Aviv 1972) vol. 1 págs. 13-37: págs. 19-26. Véase asímismo Dumont "Structure" págs. 351-393. 
pesar de esta disposición todavía quedaron excluidas del reconocimiento algunas familias.

Ahora bien, aunque Grecia había admitido a aquellos sefardíes como súbditos españoles, hasta 1927 no les reconoció la nacionalidad española y solamente a un grupo no superior a setenta. Una vez confirmada la noticia, el nuevo cónsul español en Salónica, Ramón Nova ${ }^{36}$, lo hacía saber en correspondencia con España:

habiéndose reconocido durante el transcurso de este próximo pasado año 1927 la nacionalidad española a unos sesenta y tantos de estos protegidos israelitas, parece natural en su consecuencia estén sujetos al cumplimiento de sus obligaciones, como tales ciudadanos españoles, entre las que figuran el cumplimiento de la Ley de Reclutamiento y Reemplazo del ejército por ellos o sus hijos que por su edad militar están comprendidos en dicha ley.

En principio el cónsul pensaba que parecía natural que los nuevos súbditos españoles comprendidos dentro de esa edad estuvieran obligados a cumplir la referida ley militar, pero como en el curso de los tres últimos años el Gobierno de S. M. había dictado varios Reales Decretos modificando en sentido favorable estas obligaciones para los españoles residentes en la América española y Estados Unidos, creía oportuno informarse en previsión de que los citados beneficios hubiesen sido extendidos con carácter general a todos los españoles residentes en el extranjero.

Estos hechos se producían tres años después del Real Decreto de 20 de marzo de 1924 por el que el general Primo de Rivera otorgaba la nacionalidad española a todos los israelitas que acreditasen ser descendientes de los judíos oriundos de España y la solicitasen antes del 31 de diciembre de 1930. A pesar del alcance de esta medida sólo unos pocos sefardíes de Salónica y de otros lugares aceptaron la oferta, pues la mayoría no estaban interesados ${ }^{37}$.

\footnotetext{
${ }^{36}$ AMAE, Corresp. (Salónica), leg. 2.042: Despacho del cónsul de España en Salónica, Ramón Nova, al ministro de Estado (Salónica 16 en. 1928).

${ }^{37}$ J. LyNCH, "España tras la expulsión", en Los judios de España, ed. Kedourie, págs. 147-172: pág. 169.
} 
Y ello se explica por dos razones. En primer lugar porque los judíos sólo buscaban la inscripción en el consulado de Salónica para evitar ser llamados a filas, pero una vez terminada la guerra ya no necesitaban la nacionalidad española. $Y$ en segundo lugar, porque no estaban dispuestos a abandonar su posición económica en Grecia, dada la inestable situación política de España tras la dimisión del general Primo de Rivera en 1930, antes de que expirase el plazo de la presentación de solicitudes para obtener la nacionalidad española.

\section{El JUDEOESPAÑol: UNA LENGUA OLVIDADA}

El interés de España hacia los sefardíes comenzó a principios del siglo XX, aunque es durante la centuria decimonónica cuando se producen los primeros acercamientos entre ambos pueblos. No podemos dejar de reconocer la labor del doctor Pulido para conseguirlo con sus campañas entre 1904 y 1905, que se prolongan durante los años siguientes y sirven de factor desencadenante para poner nuevamente en contacto a los judíos sefardíes con España. El objetivo fue, sobre todo, crear una toma de conciencia, tanto de sefardíes como de españoles, sobre la necesidad de un acercamiento ${ }^{38}$.

Como ya he mencionado en otro artículo ${ }^{39}$, Pulido fue el primero en descubrir la colonia de judíos de Salónica, aquellos españoles ignorados que seguían manteniendo la cultura, la lengua y las costumbres de sus antepasados. Fue también el primero en poner de manifiesto la urgente necesidad de proteger los intereses españoles en el Oriente mediterráneo desde el punto de vista cultural, sobre todo respecto a su lengua, que el gobierno de Atenas, tras la anexión de Salónica en 1913, amenazaba en estos términos:

Los griegos, imitando la política seguida por Francia e Italia, clamaban por la desaparición del español entre los sefarditas, aprovechando el sabido argumento: Es una lengua inútil, puesto que no es el castellano, a fuerza de haberse corrompido, y conviene sustituirla por otra ${ }^{40}$.

${ }^{38}$ I. González García, "El regreso de los sefarditas a España (1854-1924)", en Los judios de España, ed. Méchoulan, págs. 83-87: pág. 86.

39 MorClllo "Hispania" págs. 74-75.

${ }^{40}$ AMAE, Corresp. (Salónica), leg. 2.042: Despacho del cónsul de España en Salónica, Manuel de la Escosura, al ministro de Estado (Salónica 30 en. 1914). 
Recordemos que el judeoespañol, cuyas raíces están en las lenguas hispanas habladas en la Península a fines del siglo XV, se había ido alejando gradualmente de ellas a medida que disminuía el contacto con España ${ }^{41}$.

La postura del gobierno griego contrasta, sin embargo, con el pensamiento del publicista Samuel Leví, redactor jefe del diario salonicense "La Época» a principios del siglo XX, que se manifestaba así:

Este judeo-español, ¡cuántos desagradamientos él me costó! Desde doce á trece años que las circunstancias me hicieron el defensor de este idioma que yo aficiono, sería difícil de contar la cuantidad de polémicas que sostuve con todos los adversarios del judeo-español ${ }^{42}$.

Vale la pena explicar, afirmaba Samuel Leví, la causa que llevó a "La Época" a convertirse en el campeón del judeoespañol:

Hacen catorce años algunos pretendidos periodistas judíos se metieron en mientes de hacernos abandonar nuestro idiomamadre por adoptar otro: el turco, el francés ó el italiano. Lo que hay de más extraño es que estos gaceteros escribían ellos mesmos en malo judeo-español y vivían de esta jerigonza. Ellos nos acusavan de persistir á hablar una lengua que debíamos aborrecer visto las sofriendas [sic, sofrienzas] (souffrances) que nuestros abuelos soportaron en España. Fuera de este punto que agitaba en nosotros la fibra nacional, los otros argumentos me parecían muy poco serios. $Y$ las discusiones empezaron. Empezadas sobre el tono el más cortés, las polémicas degeneravan siempre en personalidades. Los adversarios del judeo-español empleaban razonamientos poco basados á los cuáles nos esforzávamos de oponer la lógica, la ciencia, la historia, y sobre todo, el ejemplo. Por dar más fuerza a la causa que sosteníamos en la "Época", yo agrupé á mi rededor

${ }^{41}$ I. M. HASSÁN, "El español sefardí (judeoespañol, ladino) (1)», Boletín Informativo (Fundación Juan March) 243 (1994) págs. 3-16: pág. 6; Rodrigue "Sefardíes" pág. 184. Existe abundante bibliografía sobre el judeoespañol; puede consultarse al respecto D. Bunis, Sephardic Studies: A Research Bibliography incorporating Judezmo Language, Literature and Folklore, and Historical Background (Nueva York 1981).

${ }^{42}$ Citado por L. Martine, "El doctor Pulido, apóstol de los sefardíes", Historia 16105 (1985) págs. 19-24: pág. 23. 
cerca treinta mansevos (jóvenes salidos todos de las Escuelas de la Alliance Israélite) que se metieron a colaborar con actividad, por inculcar un espíritu nuevo, por dar nueva sangre a nuestras gacetas. Fuera de ésta yo emprendí, mientras tres años, viajes circulares en todo el Oriente, ande hice conferencias sobre cuestiones nacionales y particularmente sobre el judeo-español ... ${ }^{43}$.

El colectivo de judíos españoles, temeroso ante la política griega, hacía un llamamiento al gobierno de Madrid a través de su cónsul Manuel de la Escosura, aprovechando las simpatías que el propio rey Alfonso XIII sentía hacia los sefardíes de Salónica, para que adoptase las soluciones oportunas al respecto, conducentes a purificar el idioma entre los hebreos y crear una base sólida de influencia intelectual, comercial y política.

Para poder conseguir tales objetivos, un grupo de sefardíes solicitaba a España el envío de gramáticas, diccionarios, libros de texto, obras clásicas, etc., para donarlas a las bibliotecas israelitas. Incluso pedían la implantación de escuelas en Salónica, para que los judíos allí residentes pudieran perfeccionar su lengua y sus descendientes la llegasen a hablar como en España. De forma muy diferente debió pensar el gobierno ateniense, cuando propuso que se multiplicasen las instituciones de estudios helenos y que abriesen sus puertas a todos los judíos. En breve, pensaba el ejecutivo, los sefardíes hablarán la lengua griega ${ }^{44}$.

En cualquier caso, y como ya he expuesto en otro lugar ${ }^{45}$, mientras los judíos esperaban la respuesta a todas sus peticiones y Grecia se empeñaba en que desapareciese el judeoespañol, salía a la luz la primera revista de habla española en Salónica, "Hispania», con la ayuda del periodista y comerciante español Domingo Solé, que se hallaba en Atenas desde 1918. El primer número apareció en 1919; después se publicaría en Atenas, vendiéndose posteriormente en El Pireo, Constantinopla, Esmirna y España.

\footnotetext{
${ }^{43}$ Martine "Pulido» pág. 23.

${ }^{44}$ Nordau "Grecia” págs. 5-6.

${ }^{45}$ Morcillo "Hispania” pág. 71; AMAE, Polít. (Grecia), leg. 2.517: Despacho del cónsul de España en Grecia, Teodoro Varela y Gil, al ministro de Estado (Salónica 26 mar. 1919).
} 
A través de ella los intelectuales israelitas dirigían un llamamiento no sólo a la prensa española, sino también al gobierno de España para que pusieran su mirada en el Oriente mediterráneo. Éstas eran algunas de sus palabras:

Sin el esfuerzo y la protección oficial, las energías españolas que se desarrollaban en Oriente podían malograrse. Sobre todo, deberían pensar en Salónica, en sus 80.000 habitantes que hablaban el idioma castellano ... El problema de la instalación de escuelas españolas en Salónica es de toda urgencia, si no queremos que las próximas generaciones ignoren completamente nuestro idioma ... ${ }^{46}$.

Las potencias europeas, sin embargo, habían dado al problema una importancia trascendental. En aquella época no se encontraba a casi nadie de mediana cultura que no hablase francés. En Salónica, como en todo el Oriente mediterráneo, existían varias escuelas e instituciones francesas, italianas, inglesas e incluso alemanas, pero no españolas, a donde acudían alumnos judíos. Paralelamente se iniciaba una campaña propagandística en favor de la lengua francesa en la que participaban los sefardíes eruditos y, a través de ellos, la gente del pueblo. Los intelectuales sefardíes se dan cuenta de que su lengua es un "mal" español; y ante el dilema que se plantea entre un mal español o un buen francés, optan por el francés y el sefardí va quedando relegado a lengua familiar ${ }^{47}$; también compartían esa opinión los profesores de las escuelas francesas, para quienes el español de la época de los Reyes Católicos se había "bastardeado" hasta convertirse en un "jargón".

Al respecto señala A. J. Toynbee ${ }^{48}$ que mientras viajaba en 1921 por Oriente Próximo en un tren que se dirigía desde Salónica a Vedona, coincidió en un vagón con tres judíos maestros de escuela y un oficial griego. Los maestros de Salónica estaban muy animados y se pusieron a cantar en francés. Después de mucho cantar, el oficial dijo: “¿Por qué no cantáis en griego para variar? Este país forma ahora parte de Grecia y sois ciudadanos griegos". "Preferimos el francés", contestaron los judíos. Toynbee pensó que el comportamiento de los maestros de Salónica "daba testimonio de la relativa humanidad con que

${ }^{46}$ A. Farré, "El deber de España", Hispania 1 (1919) págs. 12-13.

${ }^{47}$ HASSÁN «El español sefardín pág. 11.

${ }^{48}$ A. J. ToYnbee, Study of History (Londres 1935) vol. 2 pág. 246. 
los judíos fueron tratados por los osmanlíes en el Imperio otomano".

Bien es verdad que si los israelitas españoles habían conservado el judeoespañol, que hablaban siempre en su vida familiar, no lo habían hecho por fidelidad a sus raíces o por amor a España, sino por fidelidad a sí mismos o por amor propio; pero cuando las circunstancias históricas hicieron necesaria una defensa de su lengua para mantenerla con vida, la inmensa mayoría de los sefardíes se desentendieron de ello, iniciándose el ocaso del judeoespañol como lengua de cultura ${ }^{49}$.

La preocupación por conservar el judeoespañol queda recogida en estas palabras del propio diplomático español Pedro de Prat:

Era frecuente encontrarse con quienes dominaban cinco o seis idiomas, pues en general, los judíos expulsados de España, además de hablar el castellano, adoptarón la lengua del país donde se refugiaron desde la segunda generación. Con aquella enorme influencia linguística, no era aventurado predecir que sin la protección de una escuela española que velase por la pureza y desarrollo de la lengua castellana, ésta estuviese llamada a desaparecer. Sería muy triste que el trabajo de más de cuatro siglos se viniera abajo en una época en que España había entrado en una nueva fase de actividad y renovación ${ }^{50}$.

Por otra parte, un grupo de intelectuales israelitas se dirigía al gobierno español a través de la revista "Hispania" en estos términos:

Salónica es el hogar español de Oriente. En manos de los judíos está todo el comercio de Grecia oriental, Macedonia, Turquía y sus costas asiáticas. España no sólo debía crear escuelas, fundar hospitales, etc., sino que también tenía que instalar bibliotecas y, sobre todo, centros comerciales y cámaras de comercio ${ }^{51}$.

Para ello contaban con la colaboración de dicha revista, la cual tenía como finalidad dar a conocer la España moderna a

\footnotetext{
${ }^{49}$ HASSÁN "El español sefardín pág. 6.

${ }^{50}$ AMAE, Polít. (Grecia), leg. 2.517: Despacho del encargado de negocios de España en Grecia, Pedro de Prat, al ministro de Estado (Atenas 3 mayo 1920).

${ }^{51}$ AMAE, Polít. (Grecia), leg. 2.517: Despacho del cónsul de España en Salónica, Teodoro Varela y Gil, al ministro de Estado (Atenas 30 mayo 1919).
} 
los israelitas de Salónica y transmitir por escrito su lengua al resto de los judíos de todo el Oriente mediterráneo, al tiempo que servía de guía a los comerciantes y exportadores españoles. Teniendo en cuenta lo útil que podía ser para España, su director Angel Dant pedía una subvención al gobierno de Madrid, al menos temporal, para ayudar a una publicación que habría de reportar grandes beneficios a sus intereses económicos y políticos. La subvención fue denegada ${ }^{52}$.

Desde Salónica, el director de dos diarios en judeoespañol, "E1 Liberal" y "El Pueblo», también pedía ayuda a España. Eran los únicos periódicos, de los 33 existentes entre 1865 y 1918, escritos en dicha lengua ${ }^{53}$, que llegaban a Macedonia y a otros países balcánicos.

El encargado de negocios Pedro de Prat, en correspondencia con el gobierno español, exponía la petición de dicho director

para perfeccionar el castellano antiguo, publicar en los citados diarios, escritos en caracteres hebraicos, regularmente todos los días, dos o tres columnas en castellano puro y con letras latinas ${ }^{54}$, las palabras no utilizadas en la lengua castellana serían explicadas allí, y así, poco a poco, el lector asimilaría el castellano y encontraría la posibilidad, con el paso del tiempo, de mantener correspondencia en español, lo que facilitaría mucho las relaciones comerciales. También podría leer revistas españolas y, en definitiva, interesarse por las cosas de España. De ese modo, lo que otros conseguirían hacer con gran fatiga, por los enormes sacrificios que conllevaba asistir a las escuelas, España lo obtendría por medios muy simples y rápidos, gracias a la supervivencia de su lengua entre aquella población, excesivamente fiel al idioma que hablaban desde hacía más de cuatro siglos ${ }^{55}$.

Para lograr su objetivo, el redactor solicitaba al gobierno de Madrid una ayuda en papel de imprenta, con el fin de que

${ }^{52}$ AMAE, Polít. (Grecia), leg. 2.517: Despacho del encargado de negocios de España en Grecia, Pedro de Prat, al ministro de Estado (Atenas 22 jul. 1919).

53 MolHo "Renouveau” pág. 71.

${ }^{54}$ Recordemos que hasta el primer cuarto del siglo XX, el judeoespañol se escribía exclusivamente con caracteres hebreos y hasta la reforma de Atatürk no empezaron a usarse los latinos, aunque en Salónica se continuó con la grafía hebrea hasta 1940.

${ }^{55}$ AMAE, Polít. (Grecia), leg. 2.517: Despacho del cónsul de España en Salónica, Teodoro Varela y Gil, al ministro de Estado (Atenas 30 mayo 1919). 
dichos periódicos pudieran añadir una hoja escrita en correcto castellano y con letras latinas ${ }^{56}$. Tampoco hubo suerte en aquella ocasión. Una vez más, el ejecutivo español se resistió a dar subvención alguna a la prensa judía, ignorando lo beneficioso que podría ser para sus intereses culturales, económicos y políticos en el Oriente mediterráneo. Había que esperar a 1924, cuando se les dio a los israelitas la oportunidad de hacerse españoles, para que muchos intelectuales y políticos se preocupasen por el tema.

\section{RESUMEN}

El hundimiento del Imperio otomano y el resurgimiento de la nueva Grecia al finalizar las guerras balcánicas en 1913 trajeron consigo numerosos problemas con los que se tuvo que enfrentar el colectivo sefardí de Salónica tras la incorporación de esta ciudad a Grecia. Nos ocupamos aquí: 1 ) de las difíciles y tensas relaciones de convivencia entre sefardíes y griegos; 2) del reconocimiento de los judíos salonicenses como súbditos españoles; y 3) del deseo de los sefardíes de conservar el judeoespañol y perfeccionar el conocimiento del español.

\section{SUMMARY}

The demise of the Ottoman Empire and the subsequent rebirth of a new Greek nation in 1913, coming as a result of the end to The War in the Balkans, set the basis for understanding, in part, many of the problems which the Salonika Sephardic community confronted as it was absorbed by the victorious Greeks. The most salient of which were: 1 ) difficult societal relations between Sephardim and Greeks; 2) knowledge that they, the Sephardim, could also claim Spanish citizenship; 3) the desire to preserve Ladino and to improve their understanding of the Spanish language.

${ }^{56}$ AMAE, Polít. (Grecia), leg. 2.517: Despacho del encargado de negocios de España en Grecia, Pedro de Prat, al ministro de Estado (Atenas 22 jul. 1919). 